\title{
Contribution of S. xylosus and L. sakei ssp. carnosus Fermentation to the Aroma of Lupin Protein Isolates
}

\author{
Katharina Schlegel ${ }^{1,2}\left(\mathbb{D}\right.$, Eva Ortner ${ }^{2}$, Andrea Buettner ${ }^{1,2}$ and Ute Schweiggert-Weisz ${ }^{2,3, *}$ \\ 1 Department of Chemistry and Pharmacy, Friedrich-Alexander-Universität Erlangen-Nürnberg, \\ 91054 Erlangen, Germany; katharina.schlegel@ivv.fraunhofer.de (K.S.); \\ andrea.buettner@ivv.fraunhofer.de (A.B.) \\ 2 Fraunhofer Institute for Process Engineering and Packaging (IVV), 85354 Freising, Germany; \\ eva.ortner@ivv.fraunhofer.de \\ 3 Institute of Nutritional and Food Sciences, University of Bonn, 53115 Bonn, Germany \\ * Correspondence: ute.weisz@ivv.fraunhofer.de; Tel.: +49-8161-491-431
}

Citation: Schlegel, K.; Ortner, E.; Buettner, A.; Schweiggert-Weisz, U. Contribution of S. xylosus and L. sakei ssp. carnosus Fermentation to the Aroma of Lupin Protein Isolates. Foods 2021, 10, 1257. https:/ /doi.org/ $10.3390 /$ foods 10061257

Academic Editor: Amparo

Gamero Lluna

Received: 19 April 2021

Accepted: 29 May 2021

Published: 1 June 2021

Publisher's Note: MDPI stays neutral with regard to jurisdictional claims in published maps and institutional affiliations.

Copyright: (c) 2021 by the authors. Licensee MDPI, Basel, Switzerland. This article is an open access article distributed under the terms and conditions of the Creative Commons Attribution (CC BY) license (https:// creativecommons.org/licenses/by/ $4.0 /)$

\begin{abstract}
Aroma-active compounds of lupin protein isolate and lupin protein isolate fermented with Staphylococcus xylosus and Lactobacillus sakei ssp. carnosus were investigated. The changes in aromaactive compounds were determined by application of aroma extract dilution analysis in combination with gas chromatography-mass spectrometry/olfactometry for identification, and by stable isotope dilution assays for quantification. A total of 30 aroma-active compounds for non-fermented and fermented samples were identified. The aroma profile of LPI fermented with Lactobacillus sakei ssp. carnosus was characterized as roasty and popcorn-like. Staphylococcus xylosus generated cheesy impressions, being in line with the fact that the main aroma compounds acetic acid, butanoic acid, and 2/3-methylbutanoic acid could be identified. Quantification of butanoic acid further confirmed these findings with the highest concentration of $140 \mathrm{mg} / \mathrm{kg}$ for LPI fermented with Staphylococcus xylosus. Our study provides insights into how fermentation utilizing different fermentative microbial strains, namely Staphylococcus xylosus and Lactobacillus sakei ssp. carnosus alters the aroma profile of lupin protein isolates. This demonstrates the potential of shaping fermented protein-based foods via targeted microbiological refinement.
\end{abstract}

Keywords: lupin protein; fermentation; Staphylococcus xylosus; Lactobacillus sakei ssp. carnosus; gas chromatography-olfactometry; aroma; stable isotope dilution analysis; odour activity value

\section{Introduction}

In recent years, an increasing trend of plant-based food products can be observed in the global market. More and more people are avoiding animal products in their diet for ethical, ecological, health and animal welfare reasons. This also increases the demand for plant-based raw materials, especially proteins, in order to continue to supply the body with sufficient amounts of the essential nutrient. Legumes, such as lupins, are promising alternatives to animal protein due to their high protein content of $39 \%$ up to $55 \%$ [1] and a balanced amino acid supply [2]. Lupin proteins are already used as ingredients in various food applications, such as mayonnaise, ice cream, bakery products and pastries, milk replacements, and pasta products [3].

The use of legumes in some food is still limited due to their functional properties, such as low solubility in the acidic range. In addition, legume proteins often have a characteristic overall aroma, which is described with green, grassy and beany aroma impressions [4-7]. In particular, these distinct sensory characteristics make it difficult to use legume proteins in food and to easily substitute animal proteins with plant proteins. This problem is often overcome by adding flavouring agents to plant-based products in order to mask the typical aroma notes. The addition of many other agents—including flavourings-often leads to criticism of plant-based products. However, if it were possible to reduce the characteristic 
aroma notes or to create desired aroma notes by means of suitable technologies, the addition of flavourings could be reduced or even dispensed with.

Fermentation is a promising approach for modifying the aroma impressions of legumes considerably. For example, lactic acid fermentation has already been shown to decrease the green smelling n-hexanal content of pea protein extracts [8]. Other studies have shown that pea-like, green, earthy and beany aroma impressions in lupin, pea and soy protein isolate were reduced or masked by fermentation [9-11].

In a previous study, lupin protein isolates were fermented with Staphylococcus xylosus and Lactobacillus sakei ssp. carnosus, respectively, to investigate the effect of fermentation on the functional and sensory properties of lupin protein isolates [11]. Schlegel, Leidigkeit, Eisner and Schweiggert-Weisz [11] observed a remarkable change in the sensory properties of the lupin proteins fermented with Staphylococcus xylosus and Lactobacillus sakei ssp. carnosus. In particular, a sweaty/cheesy and a roasty/popcorn-like impression clearly emerged. Since the changes in the sensory properties of the other microorganisms used in the study were less pronounced, it was obvious to take a closer look at the aroma profile of the lupin protein isolate fermented with Staphylococcus xylosus and Lactobacillus sakei ssp. carnosus. Commonly, both microorganisms are commonly used as starter cultures in the fermentation of meat products [12-18], but their use in the fermentation of lupin proteins is, to the best of our knowledge, reported here for the first time.

The aim of this study was to investigate the changes in the main aroma compounds of lupin protein isolates after their fermentation with Staphylococcus xylosus and Lactobacillus sakei ssp. carnosus. Therefore, an aroma extract dilution analysis in combination with gas chromatography-mass spectrometry/olfactometry was carried out for the identification of the flavor compounds. Stable isotope dilution assays were used for their quantification.

\section{Materials and Methods}

\subsection{Preparation of Lupin Protein Isolates and Fermented Lupin Protein Isolates}

Lupin protein isolate (LPI) preparation, and fermentation of the isolate with Staphylococcus xylosus (S. xylosus, DSM 20266) and Lactobacillus sakei ssp. carnosus (L. sakei ssp. carnosus, DSM 15851) for $24 \mathrm{~h}$ were prepared as previously described by Schlegel, Leidigkeit, Eisner and Schweiggert-Weisz [11]. The protein content of LPI was $89.6 \%$, and fermented LPI with S. xylosus and L. sakei ssp. carnosus contained of $80.1 \%$ and $80.6 \%$, respectively [11].

\subsection{Isolation of the Volatiles}

A total $20 \mathrm{~g}( \pm 0.3 \mathrm{~g})$ of each sample were extracted using dichloromethane (DCM, $100 \mathrm{~mL}$ ) by stirring vigorously for $30 \mathrm{~min}$ at room temperature in a closed vessel. After filtration, volatiles were separated from the non-volatiles using the solvent-assisted flavor evaporation (SAFE) technique according to Engel, et al. [19]. For a guaranteed careful and fast isolation of the volatile compounds, the SAFE distillation was performed using a high vacuum pump with a pressure of about $10^{-4} \mathrm{mbar}$, with a water bath temperature of $50{ }^{\circ} \mathrm{C}$ and an apparatus temperature of $55^{\circ} \mathrm{C}$. The obtained distillate was dried over anhydrous sodium sulfate, filtered and concentrated to $\sim 3 \mathrm{~mL}$ at $50{ }^{\circ} \mathrm{C}$ by means of Vigreux distillation (50 $\mathrm{cm} \times 1 \mathrm{~cm}$ i.d.), and finally to a total volume of $\sim 100 \mu \mathrm{L}$ by microdistillation according to Bemelmans [20].

\subsection{Gas Chromatography-Olfactometry (GC-O)}

The sample distillates were analyzed by GC-O using a Trace Ultra gas chromatograph (Thermo Fisher Scientific, Waltham, MA, USA) using a DB-FFAP (30 $\mathrm{m} \times 0.32 \mathrm{~mm}$, film thickness $0.25 \mu \mathrm{m}, \mathrm{J} \& \mathrm{~W}$ Scientific, Agilent Technologies Germany GmbH \& Co. KG, Waldbronn, Germany) capillary column. Aliquots $(2 \mu \mathrm{L})$ of the distillates were manually injected by the cold on-column technique at $40{ }^{\circ} \mathrm{C}$. After $2 \mathrm{~min}$, the temperature was raised at $8{ }^{\circ} \mathrm{C} / \mathrm{min}$ to $240{ }^{\circ} \mathrm{C}$ and held for $5 \mathrm{~min}$. The flow rate of the helium carrier gas was $2 \mathrm{~mL} / \mathrm{min}$. At the end of the capillary column, the effluent was split in a 1:1 ratio into 
an odor detection port (ODP) and a flame ionization detector (FID). The flame ionization detector and the ODP were held at $300{ }^{\circ} \mathrm{C}$ and $250{ }^{\circ} \mathrm{C}$, respectively. Linear retention indices (RIs) of the aroma-active compounds were calculated using a homologous series of n-alkanes (C6-C26 for DB-FFAP and C6-C18 for DB-5, respectively) as described by Van Den Dool and Kratz [21]. To avoid a potential lack of recognition of odorants, the aroma-active areas of the original distillate were evaluated by three trained panelists.

\subsection{Aroma Extract Dilution Analysis (AEDA)}

To enable a comparison between the fermented and non-fermented isolates, the same amounts were extracted, subjected to SAFE distillation, concentrated to the same final volume, and, finally, the same volume was used for gas chromatography-olfactometry (GCO). The flavor dilution (FD) factor of each aroma compound obtained from the distillates of LPI and fermented LPI were determined using AEDA by diluting the distillate stepwise with DCM $(1+2 ; v / v)$. GC-O analyses were performed for the undiluted distillates $(\mathrm{FD}=1)$, and all subsequent dilutions. The respective FD factor assigned correlated to the highest dilution in which the compound that was still perceivable at the ODP.

\subsection{Gas Chromatography-Mass Spectrometry/Olfactometry (GC-MS/O)}

The samples were analyzed by GC-MS/O with a Trace Ultra gas chromatograph (Thermo Fisher Scientific) and a Trace DSQ mass spectrometer (Thermo Electron Corporation, Waltham, TX, USA) using a DB-FFAP (30 $\mathrm{m} \times 0.32 \mathrm{~mm}$, film thickness $0.25 \mu \mathrm{m}$, J \& W Scientific, Agilent Technologies Germany GmbH \& Co. KG) capillary column. Aliquots of $2 \mu \mathrm{L}$ were injected via the cold on-column technique at $40{ }^{\circ} \mathrm{C}$ using a multipurpose autosampler MPS 2 (Gerstel GmbH \& Co. KG, Mühlheim an der Ruhr, Germany). After $2 \mathrm{~min}$, the temperature was raised at $8{ }^{\circ} \mathrm{C} / \mathrm{min}$ to $240{ }^{\circ} \mathrm{C}$, and held for $5 \mathrm{~min}$. The flow rate of the helium carrier gas was $2 \mathrm{~mL} / \mathrm{min}$. At the end of the capillary column, the effluent was split into an ODP and a mass spectrometer using two deactivated fused silica capillaries (0.5 m × $0.2 \mathrm{~mm}$; A-Z Analytik-Zubehör GmbH, Langen, Germany). Mass spectra in positive electron impact mode were generated at $70 \mathrm{eV}$ ionization energy with a $m / z$ range of $35-350$.

\subsection{Two-Dimensional Gas Chromatography-Mass Spectrometry/Olfactometry (2D-GC-MS/O)}

The 2D-GC-MS/O system consisted of two gas chromatography systems (Agilent Technologies Germany GmbH \& Co. KG) housing capillary columns with different polarities (DB-FFAP and DB-5, both $30 \mathrm{~m} \times 0.32 \mathrm{~mm}$, film thickness $0.25 \mu \mathrm{m}$, J \&W Scientific, Agilent Technologies Germany GmbH \& Co. KG) connected via a CTS 1 cryotrap system (Gerstel GmbH \& Co. KG). A total $2 \mu \mathrm{L}$ were injected automatically using the cold oncolumn technique at $40{ }^{\circ} \mathrm{C}$ by a Multipurpose Sampler MPS 2XL (Gerstel GmbH \& Co. $\mathrm{KG}$ ). At the end of the capillary column of the first GC system the effluent was split 1:1 by volume and led to an $\operatorname{ODP}\left(290^{\circ} \mathrm{C}\right)$ and FID $\left(240^{\circ} \mathrm{C}\right)$. After $2 \mathrm{~min}$, the temperature was raised at $8^{\circ} \mathrm{C} / \mathrm{min}$ to $230^{\circ} \mathrm{C}$, and held at the final temperature for $5 \mathrm{~min}$ in the first GC oven. The helium carrier gas flow was $8 \mathrm{~mL} / \mathrm{min}$. Afterwards, the aroma-active areas of interest were transferred to the cryogenic trap $\left(-100^{\circ} \mathrm{C}\right)$. After thermodesorption in the second GC system at $250{ }^{\circ} \mathrm{C}$, the volatiles were transferred to the second column at a starting temperature of $40{ }^{\circ} \mathrm{C}$. The temperature was raised at $8{ }^{\circ} \mathrm{C} / \mathrm{min}$ to a final temperature of $250{ }^{\circ} \mathrm{C}$ and held for $1 \mathrm{~min}$. At the end of the capillary of the second GC system, the effluent was split and passed in equal parts to both an ODP and a MS. Mass spectra were recorded in positive electron impact ionization mode at $70 \mathrm{eV}$ ionization energy. The $\mathrm{m} / \mathrm{z}$ range was 35-399.

\subsection{Quantification of Aroma-Active Compounds}

The quantification of the selected aroma compounds acetic acid, butanoic acid, 2acetyl-1-pyrroline, 4-hydroxy-2,5-dimethyl-3(2H)-furanone and 3-(methylthio)propanal in LPI and fermented LPI was carried out using stable isotope dilution assays. Different 
amounts of sample material (1-5 g; depending on the concentrations of the respective odorants determined in preliminary experiments) were used for quantitation of the aromaactive compounds. The isotopically labeled internal standards were dissolved and stored in dichloromethane.

A suspension of the respective sample material, $100 \mathrm{~mL} \mathrm{DCM}$ and the labeled internal standards (amounts depending on the concentrations of the analytes) were stirred ( $300 \mathrm{rpm}$ ) for $30 \mathrm{~min}$ at room temperature in a closed vessel. Further workup was performed as described above for the isolation of the volatiles. The quantitation experiments were performed in duplicates. The quantitation was performed via gas chromatography-mass spectrometry (GC-MS) or two-dimensional high-resolution gas chromatography-mass spectrometry (2D-GC-MS) as described above.

Determination of response factors: for each odorant, a response factor was calculated by analyzing binary mixtures of defined amounts of the unlabeled analyte and the labeled standard in five different mass ratios (5:1, 3:1, 1:1, 1:3, 1:5) under the same chromatography conditions used for the samples.

\subsection{Orthonasal Odor Thresholds (OT)}

For the calculation of odor activity values (OAVs), orthonasal odor thresholds (OTs) of selected aroma compounds were taken from Czerny, et al. [22].

\section{Results}

\subsection{Identification of Aroma-Active Volatile Organic Compounds (VOC)}

First, the volatiles were extracted from the protein isolates by DCM followed by high vacuum distillation using the SAFE technique. The distillates obtained of each kind of protein isolate exhibited the typical characteristic overall aroma, when a drop of the distillate was put on a strip of filter paper, proving the successful extraction of all key aroma compounds. Next, the distillates were subjected to AEDA as a screening method for differentiation between aroma-active VOC and the bulk of odorless VOC. Application of AEDA by GC-O revealed in total 30 aroma-active regions for all samples in an FD factor range between 1 and $\geq 6561$ (Table 1 ). The GC-O analyzes of the non-fermented lupin protein isolate (LPI) distillate resulted in the detection of 28 aroma-active regions in the undiluted distillate (FD 1) performing the GC-O analyses on a DB-FFAP capillary column. Six of these compounds (no. 23, 25, 26, 27, 29,30) were still perceivable in the highest FD factor of 729. However, it is important to note, that the most intense aroma-active regions did not correlate with the highest FID peak signals. Trace substances may belong to the potent aroma contributors whereas the quantitative dominance of a volatile substance may not be directly correlated with an overall aroma impact.

Analysis of the distillates obtained from the LPI fermented with S. xylosus and L. sakei ssp. carnosus resulted in the detection of 30 aroma-active regions in each of the respective undiluted distillates (FD 1). Three aroma-active regions (no. 15, 24, 28) in LPI fermented with $S$. xylosus were detected within the highest FD factor of $\geq 6561$. For LPI fermented with L. sakei ssp. carnosus, five regions (no. 16 a/b, 22, 26, 29, 30) were perceived within the highest FD factor of 729. For unequivocal identification of the most potent aroma-active compounds, the respective odor quality and intensity perceived at the odor detection port, the retention indices on two capillary columns of different polarities, and mass spectra in EI mode recorded by GC-MS/O and 2D-GC-MS/O (if trace odorants coeluted with other volatiles present in higher amounts) were compared with the data of reference compounds. 


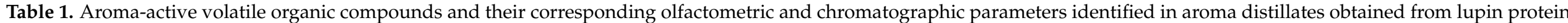
isolates (LPI) and with S. xylosus (DSM 20266) and L. sakei ssp. carnosus (DSM 15831) fermented LPI.

\begin{tabular}{|c|c|c|c|c|c|c|c|}
\hline \multirow{2}{*}{ No. ${ }^{a}$} & \multirow{2}{*}{ Aroma-Active Compound } & \multirow{2}{*}{ Aroma Quality ${ }^{b}$} & \multicolumn{2}{|c|}{ RI Value ${ }^{c}$ on } & \multicolumn{3}{|c|}{ FD Factor ${ }^{d}$} \\
\hline & & & DB-FFAP & DB-5 & LPI & S. xylosus & L. sakei ssp. carnosus \\
\hline 1 & hexanal $^{\mathrm{f}}$ & grassy, green & 1050 & 800 & 1 & 1 & 1 \\
\hline 2 & 1-octen-3-one e & mushroom-like & 1287 & 979 & 9 & 3 & 9 \\
\hline 3 & 2-acetyl-1-pyrroline ${ }^{\mathrm{f}}$ & roasty, popcorn-like & 1320 & 932 & 3 & 3 & 9 \\
\hline 4 & (Z)-1,5-octadien-3-one ${ }^{\mathrm{f}}$ & geranium-like & 1252 & 982 & 1 & 1 & 1 \\
\hline 5 & nonanal $^{\mathrm{e}}$ & soapy & 1318 & 1104 & 1 & 1 & 1 \\
\hline 6 & acetic acid $^{\mathrm{e}}$ & vinegar-like & 1403 & 619 & 9 & 729 & 27 \\
\hline 7 & 3-isopropyl-2-methoxypyrazine ${ }^{\mathrm{e}}$ & pea-like, green bell pepper-like & 634 & 1084 & 9 & 3 & 3 \\
\hline 8 & 3-(methylthio)propanal ${ }^{\mathrm{f}}$ & cooked potato-like & 1398 & 905 & 9 & 3 & 3 \\
\hline 10 & $(E)$-non-2-enal ${ }^{\mathrm{e}}$ & fatty, cardboard-like & 1500 & 1188 & 9 & 1 & 1 \\
\hline 11 & 3-isobutyl-2-methoxypyrazine $\mathrm{f}$ & pea-like, green bell pepper-like & 1500 & 1182 & 9 & 1 & 3 \\
\hline 12 & (Z)-non-2-enal ${ }^{\mathrm{e}}$ & cardboard-like, fatty & 1495 & 1127 & 9 & 3 & 3 \\
\hline 13 & methylpropanoic acid ${ }^{\mathrm{f}}$ & cheesy, sweaty & 1509 & 1937 & $<1$ & 3 & 3 \\
\hline 14 & $(E, Z)$-nona-2,6-dienal $\mathrm{e}$ & cucumber-like & 1500 & 1123 & 9 & 3 & 3 \\
\hline 15 & butanoic acid $^{\mathrm{e}}$ & cheesy & 1600 & 804 & $<1$ & $\geq 6561$ & 243 \\
\hline $16 a / 16 b$ & 2-methylbutanoic acid/3-methylbutanoic acid e & sweaty, cheesy & 1643 & 861 & 9 & 729 & 729 \\
\hline 17 & $(E, Z)$-nona-2,4-dienal ${ }^{\mathrm{e}}$ & fatty, cucumber-like, cardboard-like & 1650 & 1189 & 9 & 81 & 3 \\
\hline 18 & 3-hydroxy-2-methyl-pyran-4-one ${ }^{\mathrm{e}}$ & caramel-like & 1947 & 1130 & 3 & 81 & 1 \\
\hline 19 & trans-4,5-epoxy- $(E)$-dec-2-enal ${ }^{\mathrm{f}}$ & metallic & 1963 & 1375 & 9 & 729 & 9 \\
\hline 22 & 4-hydroxy-2,5-dimethyl-3(2H)-furanone $\mathrm{e}$ & caramel-like & 2035 & 1196 & 3 & 81 & 729 \\
\hline 23 & $\delta$-nonalactone $\mathrm{e}^{\mathrm{e}}$ & coconut-like & 2052 & 1360 & 729 & 3 & 9 \\
\hline 24 & $\gamma$-decalactone ${ }^{\mathrm{f}}$ & peach-like & 2116 & 1472 & 3 & $\geq 6561$ & 3 \\
\hline 25 & nonanoic acid $\mathrm{e}$ & soapy & 2150 & 1270 & 729 & 9 & 81 \\
\hline 26 & $\delta$-decalactone $\mathrm{f}^{\mathrm{f}}$ & coconut-like & 2166 & 1501 & 729 & 729 & 729 \\
\hline 27 & 3-hydroxy-4,5-dimethylfuran-2(5H)-one ${ }^{\mathrm{f}}$ & savory -like & 2200 & 1102 & 729 & 243 & 243 \\
\hline 28 & $\gamma$-dodecalactone $\mathrm{f}^{\mathrm{f}}$ & peach-like, flowery & 2334 & 1680 & 9 & $\geq 6561$ & 9 \\
\hline 29 & phenylacetic acid ${ }^{\mathrm{f}}$ & bee wax-like, honey-like & 2510 & 1256 & 729 & 729 & 729 \\
\hline 30 & 4-hydroxy-3-methoxy-benzaldehyde ${ }^{e}$ & vanilla-like & 2524 & 1395 & 729 & 729 & 729 \\
\hline
\end{tabular}

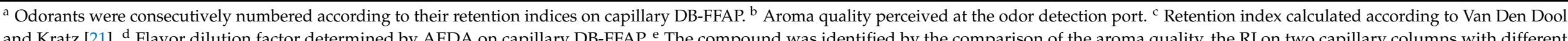

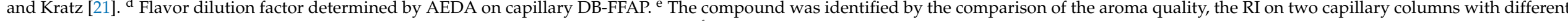

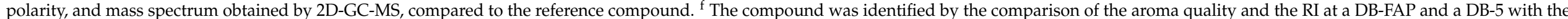
reference compound. 
As a result, in all samples fatty smelling aroma-active VOC were identified as the aldehydes (E)-non-2-enal (no. 10), (Z)-non-2-enal (no. 12), (E,Z)-nona-2,6-dienal (no. $14)$ and $(E, Z)$-nona-2,4-dienal (no. 17), whereas a metallic note was elicited by trans-4,5epoxy-(E)-dec-2-enal (no. 15). The grassy, green and soapy smelling regions derived from hexanal (no. 1) and nonanal (no. 5). In addition, coconut-like and peach-like aroma-active regions derived from lactones such as $\gamma$-nonalactone (no. 20), $\delta$-nonalactone (no. 23), $\gamma$-decalactone (no. 24), $\delta$-decalactone (no. 26) and $\gamma$-dodecalactone (no. 28). Pea-like, green bell pepper-like aroma-active regions belonged to the class of pyrazines, such as 3-isopropyl-2-methoxypyrazine (no. 7), 3-sec-butyl-2-methoxypyrazine (no. 9) and 3isobutyl-2-methoxypyrazine (no. 11). Cheesy and vinegar-like aroma impressions were identified as methylpropanoic acid (no. 13), butanoic acid (no. 15), 2-/3-methylbutanoic acid (no. $16 \mathrm{a} / \mathrm{b}$ ), and acetic acid (no. 6). Apart from that, mushroom-like and geraniumlike impressions were traced back to 1-octen-3-one (no. 2) and (Z)-1,5-octadien-3-one (no. 4). Moreover, 2-acetyl-1-pyrroline (no. 3; roasty/popcorn-like), 3-(methylthio)propanal (no. 8; cooked potato-like), 3-hydroxy-2-methyl-pyran-4-one (no. 18; caramel-like), octanoic acid (no. 21; musty/coriander-like/fatty), and 4-hydroxy-2,5-dimethyl-3(2H)-furanone (no. 22; caramel-like) were identified. In addition, nonanoic acid (no. 25; soapy), 3-hydroxy-4,5dimethylfuran-2(5H)-one (no. 27; savory-like), 4-hydroxy-3-methoxy-benzaldehyde (no. 30; vanilla-like), and phenylacetic acid (no. 29; bee wax-like/honey-like) were successfully identified in the lupin protein isolates.

\subsection{Quantification of Aroma-Active Compounds by Stable Isotope Dilution Assays (SIDA)}

Next, five selected odorants either based on the main aroma impressions previously described in sensory analyses using comparative aroma profile analyses or differing in their FD factor during AEDA (Table 1) were quantified in non-fermented and fermented LPI by means of SIDAs using the respective stable isotopically labeled internal standards (Table 2).

Table 2. Selected ions $(m / z)$ of analytes and stable isotopically labeled internal standards as well as response factors (Rf) used in stable isotope dilution assays for quantitation of five selected odorants in non-fermented LPI and fermented LPI with S. xylosus (DSM 20266) and L. sakei ssp. carnosus (DSM 15831).

\begin{tabular}{ccccc}
\hline \multirow{2}{*}{ Aroma-Active Compound } & \multirow{2}{*}{ Isotope Label } & \multicolumn{2}{c}{ Ion $(\mathrm{m} / \boldsymbol{z})$} & \multirow{2}{*}{$\mathbf{R}_{\mathbf{f}}$} \\
\cline { 3 - 4 } & & Analyte & Standard & \\
\hline acetic acid & ${ }^{13} \mathrm{C}_{2}$ & 60 & 62 & 0.99 \\
butanoic acid & ${ }^{13} \mathrm{C}_{2}$ & 88 & 90 & 0.74 \\
2-acetyl-1-pyrroline & ${ }^{2} \mathrm{H}_{3-5}$ & 111 & $114-116$ & 0.89 \\
4-hydroxy-2,5-dimethyl-3(2H)-furanone & ${ }^{13} \mathrm{C}_{2}$ & 128 & 130 & 1.01 \\
3-(methylthio)propanal & ${ }^{2} \mathrm{H}_{3}$ & 48 & 51 & 1.08 \\
\hline
\end{tabular}

Quantification revealed the highest concentration for acetic acid in all samples with the highest amount of $2500.0 \mathrm{mg} / \mathrm{kg}$ for S. xylosus (Table 3). For LPI fermented with $L$. sakei ssp. carnosus and non-fermented LPI concentrations of $83.0 \mathrm{mg} / \mathrm{kg}$ and $13.0 \mathrm{mg} / \mathrm{kg}$ were determined, respectively. Butanoic acid was quantified in the samples fermented with S. xylosus and L. sakei ssp. carnosus with amounts of $140.0 \mathrm{mg} / \mathrm{kg}$ and $15.0 \mathrm{mg} / \mathrm{kg}$, respectively, and with a concentration of $570.0 \mu \mathrm{g} / \mathrm{kg}$ for non-fermented LPI. 2-Acetyl-1pyrroline was present in concentrations of $15.0 \mu \mathrm{g} / \mathrm{kg}$ (LPI), $14.0 \mu \mathrm{g} / \mathrm{kg}$ (S. xylosus) and $14.0 \mu \mathrm{g} / \mathrm{kg}$ (L. sakei ssp. carnosus) and 3-(methylthio)propanal with $2.8 \mu \mathrm{g} / \mathrm{kg}$ (S. xylosus), $2.7 \mu \mathrm{g} / \mathrm{kg}$ (LPI), and $2.4 \mu \mathrm{g} / \mathrm{kg}$ (L. sakei ssp. carnosus). The 4-Hydroxy-2,5-dimethyl-3(2H)furanone was quantified in the fermented samples $S$. xylosus and L. sakei ssp. carnosus with amounts of $45.0 \mu \mathrm{g} / \mathrm{kg}$ and $50.0 \mu \mathrm{g} / \mathrm{kg}$, respectively, but were found to be below the limit of quantification (LOQ) for non-fermented LPI. 
Table 3. Concentration of five selected aroma-active compounds in non-fermented LPI and with S. xylosus (DSM 20266) and L. sakei ssp. carnosus (DSM 15831) fermented LPI determined using stable isotope dilution analysis (SIDA).

\begin{tabular}{|c|c|c|c|c|c|c|}
\hline \multirow{3}{*}{ Aroma Compound } & \multicolumn{6}{|c|}{ Concentration $(\mu \mathrm{g} / \mathrm{kg})$} \\
\hline & \multicolumn{2}{|r|}{ LPI } & \multicolumn{2}{|r|}{ S. xylosus } & \multicolumn{2}{|c|}{ L. sakei ssp. carnosus } \\
\hline & Mean $^{a}$ & Range $^{b}$ & Mean $^{a}$ & Range $^{b}$ & Mean $^{a}$ & Range $^{b}$ \\
\hline acetic acid & $13,000.0$ & $9100.0-15,000.0$ & $2,500,000.0$ & $2,100,000.0-2,900,000.0$ & $83,000.0$ & $77,000.0-87,000.0$ \\
\hline butanoic acid & 570.0 & $330.0-960.0$ & $140,000.0$ & $120,000.0-150,000.0$ & $15,000.0$ & $13,000.0-19,000.0$ \\
\hline 2-acetyl-1-pyrroline & 15.0 & 15.0 & 14.0 & $13.0-14.0$ & 14.0 & $13.0-14.0$ \\
\hline $\begin{array}{l}\text { 4-hydroxy-2,5-dimethyl- } \\
3(2 H) \text {-furanone }\end{array}$ & $<\mathrm{LOQ}^{\mathrm{c}}$ & $<$ LOQ & 45.0 & $44.0-46.0$ & 50.0 & $33.0-77.0$ \\
\hline 3-(methylthio)propanal & 2.7 & $2.6-2.8$ & 2.8 & $2.7-3.0$ & 2.4 & $2.3-2.5$ \\
\hline
\end{tabular}

${ }^{\text {a }}$ Mean value calculated from $n(n=3)$ determinations. ${ }^{\mathrm{b}}$ Concentration range from $n$ determinations. ${ }^{\mathrm{c}}$ Limit of quantification, $\mathrm{LOQ} \leq 19.7 \mu \mathrm{g} / \mathrm{kg}$.

\subsection{Odor Activity Values (OAV)}

OAVs are defined as the ratio of the concentration of an aroma substance in a sample to its odor threshold and are indicative of the relative importance of an individual aroma substance to the overall aroma. OAVs were calculated for the five quantified aroma compounds (Table 3) using odor recognition thresholds in water taken from Czerny et al. [22] and are shown in Table 4.

Table 4. Odor activity values (OAVs) of six selected aroma compounds calculated based on odor recognition thresholds (OT).

\begin{tabular}{ccccc}
\hline \multirow{2}{*}{ Aroma Compound } & \multirow{2}{*}{ OT $(\mu \mathrm{g} / \mathrm{L})^{\mathbf{a}}$} & \multicolumn{3}{c}{ OAV } \\
\cline { 3 - 5 } & & LPI & S. xylosus & L. sakei ssp. carnosus \\
\hline acetic acid & $180,000.0$ & $<1$ & 14 & $<1$ \\
butanoic acid & 7700.0 & $<1$ & 18 & 2 \\
2-acetyl-1-pyrroline & 0.1 & 124 & 113 & $<13$ \\
4-hydroxy-2,5-dimethyl- & 160.0 & $<1$ & $<1$ & 2 \\
3(2H)-furanone & 1.4 & 2 & 2 & 2 \\
3-(methylthio)propanal & &
\end{tabular}

a Orthonasal odor thresholds in water taken from Czerny et al. [22].

The highest OAV was calculated for 2-acetyl-1-pyrroline for all samples with values of 124 for LPI and 113 for S. xylosus and L. sakei ssp. carnosus fermented samples. Further, butanoic acid was found with an OAV of 18 for the sample fermented with S. xylosus, and was, therefore, potentially of higher sensory impact than the samples fermented with $L$. sakei ssp. carnosus (OAV 2) and LPI (OAV < 1). In addition, for acetic acid, an OAV > 1 was only achieved for S. xylosus (OAV 14), whereas an OAV of 2 was calculated for the remaining samples. The 4-Hydroxy-2,5-dimethyl-3(2H)-furanone did not exceed an OAV > 1 in any of the investigated samples.

\section{Discussion}

4.1. Assignment of Individual Aroma-Active Compounds to the Descriptive Aroma Impression of the Fermented Lupin Protein Isolates

The comparison of the AEDA results obtained in this study with the results from the comparative aroma profile analyses of non-fermented LPI and LPI fermented with S. xylosus and L. sakei ssp. carnosus as previously reported by Schlegel, Leidigkeit, Eisner and Schweiggert-Weisz [11] are in very good agreement. In our previous study, non-fermented LPI was primarily characterized using descriptive analyzes [11] by the retronasal aroma attributes pea-like/green bell pepper-like and oatmeal-like/fatty, followed by earthy/moldy/beetroot-like, cooked potato-like and roasty/popcorn-like aroma impressions. LPI fermented with S. xylosus exhibited an intense cheesy aroma impression followed by a moderate intensity of oatmeal-like/fatty impressions. LPI fermented with $L$. 
sakei ssp. carnosus was described with popcorn-like/roasty as main aroma characteristic, followed by oatmeal-like/fatty with a moderate intensity.

The aroma attributes during aroma profiling pea-like/green bell pepper-like for LPI could be related to the presence of 3-isopropyl-2-methoxypyrazine (no. 7; pea-like/green bell pepper-like), 3-sec-butyl-2-methoxypyrazine (no. 9; pea-like/green bell pepper-like), and 3-isobutyl-2-methoxypyrazine (no. 11; pea-like/green bell pepper-like). The identified components $(E)$-non-2-enal (no. 10; fatty/cardboard-like), (Z)-non-2-enal (no. 12; cardboard-like/fatty) and (E,Z)-nona-2,4-dienal (no. 17; fatty/cucumber-like/cardboardlike) in LPI are likely to be responsible for the fatty aroma impression obtained during aroma profiling. Similar impressions and components were also detected in the samples fermented with S. xylosus and L. sakei ssp. carnosus. The aroma impression cooked potato-like and roasty/popcorn-like can be attributed to the presence of the components 3-(methylthio)propanal (no. 8; cooked potato-like) and 2-acetyl-1-pyrroline (no. 3; roasty/popcorn-like), respectively.

For all the mentioned aroma-active VOC for LPI, an FD factor of 9 was determined. Although the FD factor of the individual components was not particularly high, roasty/popcornlike and cooked potato-like impressions seem to have a high relevance for the overall aroma profile of LPI. Possibly, the presence of odorants with similar aroma impressions added up to yield the intensity of the overall sensory impression [23,24]. Additive and synergistic effects as well as suppressive effects of individual odorants are very common in aroma substance mixtures, but are not captured in the course of GC-O analyses, and can only be elaborated by additional sensory tests. The intense aroma impression cheesy in the sample fermented with $S$. xylosus was thereby likely due to the combined presence of methylpropanoic acid (no. 13; cheesy/sweaty), butanoic acid (no. 15; cheesy) and 2-/3methylbutanoic acid (no. $16 \mathrm{a} / \mathrm{b}$; sweaty/cheesy). The high FD factor of $>6561$ for butanoic acid and of 729 for 2-/3-methylbutanoic acid provide further evidence for a high relevance of the two components for the overall aroma profile of fermented LPI with S. xylosus, corresponding with the pronounced intensity of the sweaty-cheesy aroma impression in the sensory evaluation. The main aroma impression roasty/popcorn-like of LPI fermented with L. sakei ssp. carnosus in sensory analysis can likewise come from 2-acetyl-1-pyrroline (no. 3; roasty/popcorn-like).

In summary, the sensory data strongly corresponded with the odorants identified here, as well as the AEDA results in so far as the fermented samples showed stronger sensory impressions of sweaty/cheesy (S. xylosus) and roasty/popcorn-like (L. sakei ssp. carnosus), respectively, corresponding with the observation that the AEDA showed higher FD factors for these odorants in the fermented samples compared to non-fermented LPI.

\subsection{Comparison of FD Factors of Fermented and Non-Fermented Lupin Protein Isolates and Quantification of Individual Aroma Compounds}

When comparing the identified components and respective FD factors of LPI and LPI fermented with S. xylosus and L. sakei ssp. carnosus, it can be further observed that the FD factors of the aroma-active acids were higher in the fermented samples than in non-fermented LPI. Acetic acid (no. 6) with an FD 9 for LPI was determined with a higher FD in the sample fermented with S. xylosus (FD 729) and with L. sakei ssp. carnosus (FD 27), which was supported by the quantitative data. LPI had a concentration of $13.0 \mathrm{mg} / \mathrm{kg}$, compared to $83.0 \mathrm{mg} / \mathrm{kg}$ for fermented LPI with L. sakei ssp. carnosus and a concentration of $2500.0 \mathrm{mg} / \mathrm{kg}$ acetic acid for the one fermented with S. xylosus. Correspondingly, with an OAV of 14 in samples fermented with S. xylosus, this compound was more pronounced in the same sample than in samples fermented with L. sakei ssp. carnosus and non-fermented LPI (both OAV < 1). Moreover, 2-and 3-methylbutanoic acid (no. $16 \mathrm{a} / \mathrm{b}$ ) were characterized with an FD factor of 729 in the fermented LPI, being higher than in non-fermented LPI with an FD of 9. Butanoic acid (no. 15) had an FD factor of $\geq 6561$ in LPI fermented with $S$. xylosus, being likewise considerably higher than in the sample fermented with $L$. sakei ssp. carnosus (FD 243). Butanoic acid and methylpropanoic acid (no. 13) were not detectable in the undiluted distillate of non-fermented LPI using GC-O. Quantitative analyses of 
butanoic acid confirmed the higher FD factor for LPI fermented with S. xylosus compared to L. sakei ssp. carnosus with concentrations of $140.0 \mathrm{mg} / \mathrm{kg}$ to $15.0 \mathrm{mg} / \mathrm{kg}$, respectively, whereas for LPI, a concentration of $570.0 \mu \mathrm{g} / \mathrm{kg}$ was determined. In addition, results of the OAV calculation showed values of 18 for samples fermented with S. xylosus, and 2 for L. sakei ssp. carnosus. In this case, the OAV for LPI was $<1$. The higher concentration of butanoic acid in the S. xylosus fermented sample was also consistent with sensory profiling, where the aroma impression cheesy was the main impression of the $S$. xylosus fermented sample. Nevertheless, LPI fermented with L. sakei ssp. carnosus also contained butanoic acid and 2/3-methylbutanoic acid (same FD as S. xylosus). However, these components do not appear to be of major relevance to the overall aroma profile of the L. sakei ssp. carnosus fermented sample. In addition, higher FD levels of 4-hydroxy-2,5-dimethyl-3(2H)furanone (no. 22) were determined in LPI fermented with S. xylosus (FD 81) and L. sakei ssp. carnosus (FD 729), than in LPI (FD 3). In this respect, the results of the quantitative analysis were in good agreement and showed concentrations of $50.0 \mu \mathrm{g} / \mathrm{kg}$ for the L. sakei ssp. carnosus fermented sample and $45.0 \mu \mathrm{g} / \mathrm{kg}$ for the S. xylosus fermented sample, whereas levels $<\mathrm{LOQ}(19.7 \mu \mathrm{g} / \mathrm{kg})$ were detected in non-fermented LPI. Accordingly, the calculated OAV was for all samples $<1$ and therefore most likely not of relevance for the overall aroma, although 4-hydroxy-2,5-dimethyl-3(2H)-furanone was detected during AEDA. This is due to the fact, that in AEDA the influence of the matrix on the aroma release is not effective.

While the results of the sensory analysis for LPI fermented with L. sakei ssp. carnosus showed roasty/popcorn-like as the main aroma impression, only differences in one FD range for 2-acetyl-1-pyrroline (no. 3) was detected between LPI fermented with L. sakei ssp. carnosus (FD 9), fermented with S. xylosus (FD 3) and non-fermented LPI (FD 3). This was also confirmed by the quantitative analysis of 2-acetyl-1-pyrroline by SIDA, where LPI fermented with L. sakei ssp. carnosus and S. xylosus showed a concentration of $14.0 \mu \mathrm{g} / \mathrm{kg}$ each. The highest concentration of 2-acetyl-1-pyrroline was $15.0 \mu \mathrm{g} / \mathrm{kg}$ for LPI. The odor threshold for 2-acetyl-1-pyrroline is $0.12 \mu \mathrm{g} / \mathrm{L}$ [22], resulting in relatively high OAV values despite their low concentrations in the samples. Accordingly, the obtained OAV indicates, with values of 124 for LPI and 113 for the samples fermented with S. xylosus and L. sakei ssp. carnosus, an overall contribution in all samples. Thereby, it can be assumed that the roasty/popcorn-like impression was more prominent in the fermented sample with L. sakei ssp. carnosus may be due to additive or suppressive effects of other matrix ingredients. Likewise, the aroma profile of LPI was described with a moderate intensity of a cooked potato-like note but only weak intensities of this aroma impression for fermented samples with S. xylosus and L. sakei ssp. carnosus. However, comparison of the FD factors and concentrations of 3-(methylthio)propanal (no. 8) revealed, only minor differences between all samples. The odor threshold for 3-(methylthio)propanal is $1.4 \mu \mathrm{g} / \mathrm{L}$ [22], and the resulting $\mathrm{OAV}$ of 2 indicates overall potential contribution, even if not pronounced, of this characteristic note to the aroma profiles of all samples. It can be assumed that the higher cooked potato-like impression in non-fermented LPI is also due to additive or suppressive effects of the matrix, as well as due to the lower acid content in non-fermented LPI to fermented LPI, resulting in improved prominence of such notes.

\subsection{Potential Formation of Aroma-Active Compounds}

S. xylosus and L. sakei ssp. carnosus are widely used as starter cultures in meat and sausage fermentation. Their metabolic pathways and products as well as the formation of aroma-active VOC have already been described in numerous studies. Acetic acid is a typical aroma compound of dry fermented sausages [12,13,15,17,25-27]. The formation may result from side reactions of homofermentative carbohydrate metabolism (e.g., alternative degradation of pyruvate) that occur in lactic acid bacteria as well as in staphylococci $[12,26]$. Another way of acetic acid production is by fatty acid oxidation and by alanine catabolism [28]. Butanoic acid is often identified in meat fermentation with $S$. xylosus und L. sakei ssp. carnosus and sausage products [12,13,25]. It is known that butanoic acid is formed from pyruvate, which is produced during the metabolism of sugars. 2- 
and 3-methylbutanoic acid and 2-methylpropanoic acid belong to the commonly occurring important aroma compounds of dry fermented sausage with S. xylosus and L. sakei ssp. carnosus $[13,16-18,25,29,30]$. Branched-chain amino acids (BCAAs), such as leucine, isoleucine, and valine, are thereby the main source of 2- and 3-methylbutanoic acid and 2methylpropanoic acid [13,14,16,31,32]. Leucine is present in LPI from Lupinus angustifolius L. cultivar Boregine with a content of about $7 \%$ and isoleucine and valine with contents of about $4 \%$ and $3 \%$, respectively [2]. In the present study, the degradation of amino acids was not investigated. Therefore, no conclusion on the course of the biosynthetic pathways and their modulation by metabolic processes can be drawn. Apart from that, $\delta$ - and $\gamma$-nonalactone, -decalactone and dodecalactone are important aroma compounds in some fermented fruit, dairy, and meat products [33]. They can be formed from free fatty acids during fermentation [33], or they can be generated thermally induced from $\delta$ and $\gamma$-hydroxy acids or triglycerides [34]. Possibly, the higher FD factors of the aroma components $\gamma$-nonalactone, $\gamma$-decalactone, and $\gamma$-dodecalactone in fermented LPI with $S$. xylosus is due to an intensified formation of free fatty acids during fermentation. However, such postulated formation pathways would require more detailed investigation of the formation/degradation of free fatty acids. Finally, 2-acetyl-1-pyrroline and 4-hydroxy2,5-dimethyl-3(2H)-furanone have been described as thermally induced volatiles from proline [35,36] and sugar [37], respectively, [35] and were reported in several foods such as dairy products, popcorn and bread [35-37]. Their occurrence is, accordingly, likewise plausible, and completes our overall understanding of the characterizing odorants that form the aroma profiles of the fermented plant proteins.

\section{Conclusions}

Fermentation with S. xylosus and L. sakei ssp. carnosus affects the aroma profile of lupin protein isolate. Identification of aroma-active VOC by GC-O in fermented lupin protein isolate showed similarities to aroma compounds formed during fermentation of meat and sausage products (acetic acid, butanoic acid, 2-/3-methylbutanoic acid). Nevertheless, the aroma profile was characterized as cheesy after fermentation with S. xylosus and as roasty, popcorn-like with $L$. sakei ssp. carnosus. Lupin protein isolate fermented with $S$. xylosus could therefore be a promising approach for the production of plant-based cheese alternatives without the addition of flavorings. L. sakei ssp. carnosus could be suitable for its use in, e.g., meat alternatives or baked goods due to its roasty aroma profile.

This study shows that fermentation could be a promising approach for the development of protein ingredients with tailor-made sensory properties. As the effect of fermentation strongly depends on the starter culture and the raw material used, it is worth investigating even more microorganisms and fermenting even more raw materials. This could expand the range of plant proteins and thus serve the ever-growing market for protein ingredients with new fermented products. These ingredients can then be used for the development of alternatives to animal products without the addition of a long ingredients list.

Author Contributions: Conceptualization, K.S., A.B. and U.S.-W.; methodology, K.S., E.O. and A.B.; formal analysis, K.S.; investigation, K.S.; writing—original draft preparation, K.S.; writing-review and editing, E.O., A.B. and U.S.-W. All authors have read and agreed to the published version of the manuscript.

Funding: This research received no external funding.

Institutional Review Board Statement: Not applicable.

Informed Consent Statement: Not applicable.

Acknowledgments: This work was supported by the Fraunhofer-Zukunftsstiftung.

Conflicts of Interest: The authors declare no conflict of interest. 


\section{References}

1. Bähr, M.; Fechner, A.; Hasenkopf, K.; Mittermaier, S.; Jahreis, G. Chemical composition of dehulled seeds of selected lupin cultivars in comparison to pea and soya bean. LWT Food Sci. Technol. 2014, 59, 587-590. [CrossRef]

2. Vogelsang-O'Dwyer, M.; Bez, J.; Petersen, I.; Joehnke, M.; Detzel, A.; Busch, M.; Krueger, M.; Ispiryan, L.; O’Mahony, J.; Arendt, E.; et al. Techno-Functional, Nutritional and Environmental Performance of Protein Isolates from Blue Lupin and White Lupin. Foods 2020, 9, 230. [CrossRef] [PubMed]

3. Van de Noort, M. Chapter 10-Lupin: An Important Protein and Nutrient Source. In Sustainable Protein Sources; Nadathur, S.R., Wanasundara, J.P.D., Scanlin, L., Eds.; Academic Press: San Diego, CA, USA, 2017; pp. 165-183. [CrossRef]

4. Bader, S.; Czerny, M.; Eisner, P.; Buettner, A. Characterisation of odour-active compounds in lupin flour. J. Sci. Food Agric. 2009, 89, 2421-2427. [CrossRef]

5. Meinlschmidt, P.; Sussmann, D.; Schweiggert-Weisz, U.; Eisner, P. Enzymatic treatment of soy protein isolates: Effects on the potential allergenicity, technofunctionality, and sensory properties. Food Sci. Nutr. 2016, 4, 11-23. [CrossRef]

6. García Arteaga, V.; Kraus, S.; Schott, M.; Muranyi, I.; Schweiggert-Weisz, U.; Eisner, P. Screening of Twelve Pea (Pisum sativum L.) Cultivars and Their Isolates Focusing on the Protein Characterization, Functionality, and Sensory Profiles. Foods 2021, 10, 758. [CrossRef] [PubMed]

7. Schlegel, K.; Lidzba, N.; Ueberham, E.; Eisner, P.; Schweiggert-Weisz, U. Fermentation of Lupin Protein Hydrolysates-Effects on Their Functional Properties, Sensory Profile and the Allergenic Potential of the Major Lupin Allergen Lup an 1. Foods 2021, 10, 281. [CrossRef] [PubMed]

8. Schindler, S.; Zelena, K.; Krings, U.; Bez, J.; Eisner, P.; Berger, R.G. Improvement of the Aroma of Pea (Pisum sativum) Protein Extracts by Lactic Acid Fermentation. Food Biotechnol. 2012, 26, 58-74. [CrossRef]

9. Garcia-Arteaga, V.; Leffler, S.; Muranyi, I.; Eisner, P.; Schweiggert-Weisz, U. Sensory Profile, Functional Properties and Molecular Weight Distribution of Fermented Pea Protein Isolate. Curr. Res. Food Sci. 2020, 4. [CrossRef]

10. Meinlschmidt, P.; Ueberham, E.; Lehmann, J.; Schweiggert-Weisz, U.; Eisner, P. Immunoreactivity, sensory and physicochemical properties of fermented soy protein isolate. Food Chem. 2016, 205, 229-238. [CrossRef]

11. Schlegel, K.; Leidigkeit, A.; Eisner, P.; Schweiggert-Weisz, U. Technofunctional and Sensory Properties of Fermented Lupin Protein Isolates. Foods 2019, 8, 678. [CrossRef] [PubMed]

12. Freiding, S.; Gutsche, K.A.; Ehrmann, M.A.; Vogel, R.F. Genetic screening of Lactobacillus sakei and Lactobacillus curvatus strains for their peptidolytic system and amino acid metabolism, and comparison of their volatilomes in a model system. Syst. Appl. Microbiol. 2011, 34, 311-320. [CrossRef]

13. Stahnke, L.H. Volatiles Produced by Staphylococcus xylosus and Staphylococcus carnosus during Growth in Sausage Minces Part II. The Influence of Growth Parameters. LWT Food Sci. Technol. 1999, 32, 365-371. [CrossRef]

14. Stahnke, L.H.; Holck, A.; Jensen, A.; Nilsen, A.; Zanardi, E. Maturity Acceleration of Italian Dried Sausage by Staphylococcus carnosus-Relationship Between Maturity and Flavor Compounds. J. Food Sci. 2002, 67, 1914-1921. [CrossRef]

15. de Vos Petersen, C.; Beck, H.C.; Lauritsen, F.R. On-line monitoring of important organoleptic methyl-branched aldehydes during batch fermentation of starter culture Staphylococcus xylosus reveal new insight into their production in a model fermentation. Biotechnol. Bioeng. 2004, 85, 298-305. [CrossRef] [PubMed]

16. Beck, H.C.; Hansen, A.M.; Lauritsen, F.R. Catabolism of leucine to branched-chain fatty acids in Staphylococcus xylosus. J. Appl. Microbiol. 2004, 96, 1185-1193. [CrossRef] [PubMed]

17. Søndergaard, A.K.; Stahnke, L.H. Growth and aroma production by Staphylococcus xylosus, S. carnosus and S. equorum-a comparative study in model systems. Int. J. Food Microbiol. 2002, 75, 99-109. [CrossRef]

18. Tjener, K.; Stahnke, L.H.; Andersen, L.; Martinussen, J. A fermented meat model system for studies of microbial aroma formation. Meat Sci. 2004, 66, 211-218. [CrossRef]

19. Engel, W.; Bahr, W.; Schieberle, P. Solvent assisted flavour evaporation-A new and versatile technique for the careful and direct isolation of aroma compounds from complex food matrices. Eur. Food Res. Technol. 1999, 209, 237-241. [CrossRef]

20. Bemelmans, J. Review of isolation and concentration techniques. Prog. Flavour Res. 1979, 8, 79-98.

21. Van Den Dool, H.; Kratz, P.D. A generalization of the retention index system including linear temperature programmed gas-liquid partition chromatography. J. Chromatogr. A 1963, 11, 463-471. [CrossRef]

22. Czerny, M.; Christlbauer, M.; Christlbauer, M.; Fischer, A.; Granvogl, M.; Hammer, M.; Hartl, C.; Hernandez, N.; Schieberle, P. Re-investigation on odour thresholds of key food aroma compounds and development of an aroma language based on odour qualities of defined aqueous odorant solutions. Eur. Food Res. Technol. 2008, 228, 265-273. [CrossRef]

23. Guadagni, D.; Buttery, R.G.; Okano, S.; Burr, H. Additive effect of sub-threshold concentrations of some organic compounds associated with food aromas. Nature 1963, 200, 1288-1289. [CrossRef] [PubMed]

24. Laska, M.; Hudson, R. A comparison of the detection thresholds of odour mixtures and their components. Chem. Senses 1991, 16, 651-662. [CrossRef]

25. Stahnke, L. Aroma components from dried sausages fermented with Staphylococcus xylosus. Meat Sci. 1994, 38, 39-53. [CrossRef]

26. Ravyts, F.; Steen, L.; Goemaere, O.; Paelinck, H.; De Vuyst, L.; Leroy, F. The application of staphylococci with flavour-generating potential is affected by acidification in fermented dry sausages. Food Microbiol. 2010, 27, 945-954. [CrossRef] 
27. Wang, Y.; Liu, R.; Ge, Q.; Wu, M.; Xu, B.; Xi, J.; Yu, H. Effects of branched-chain amino acids and Lactobacillus plantarum CGMCC18217 on volatiles formation and textural properties of dry-cured fermented sausage. Int. J. Food Sci. Technol. 2021, 56, 374-383. [CrossRef]

28. Montel, M.C.; Masson, F.; Talon, R. Bacterial role in flavour development. Meat Sci. 1998, 49, S111-S123. [CrossRef]

29. Leroy, S.; Vermassen, A.; Ras, G.; Talon, R. Insight into the Genome of Staphylococcus xylosus, a Ubiquitous Species Well Adapted to Meat Products. Microorganisms 2017, 5, 52. [CrossRef]

30. Gutsche, K.A.; Tran, T.B.T.; Vogel, R.F. Production of volatile compounds by Lactobacillus sakei from branched chain $\alpha$-keto acids. Food Microbiol. 2012, 29, 224-228. [CrossRef]

31. Smit, B.A.; Engels, W.J.; Wouters, J.T.; Smit, G. Diversity of L-leucine catabolism in various microorganisms involved in dairy fermentations, and identification of the rate-controlling step in the formation of the potent flavour component 3-methylbutanal. Appl. Microbiol. Biotechnol. 2004, 64, 396-402. [CrossRef] [PubMed]

32. Beck, H.C.; Hansen, A.M.; Lauritsen, F.R. Metabolite production and kinetics of branched-chain aldehyde oxidation in Staphylococcus xylosus. Enzym. Microb. Technol. 2002, 31, 94-101. [CrossRef]

33. Carballo, J. The role of fermentation reactions in the generation of flavor and aroma of foods. Ferment. Eff. Food Prop. 2012, 51-83. [CrossRef]

34. Forss, D.A. Mechanisms of formation of aroma compounds in milk and milk products. J. Dairy Res. 1979, 46, 691-706. [CrossRef]

35. Griffith, R.; Hammond, E.G. Generation of Swiss Cheese Flavor Components by the Reaction of Amino Acids with Carbonyl Compounds1. J. Dairy Sci. 1989, 72, 604-613. [CrossRef]

36. Karagül-Yüceer, Y.; Drake, M.; Cadwallader, K.R. Aroma-active components of nonfat dry milk. J. Agric. Food Chem. 2001, 49, 2948-2953. [CrossRef]

37. Schieberle, P. Chapter 17-New Developments in Methods for Analysis of Volatile Flavor Compounds and their Precursors. In Characterization of Food; Gaonkar, A.G., Ed.; Elsevier Science B.V.: Amsterdam, The Netherlands, 1995; pp. 403-431. [CrossRef] 